\title{
Relationship between body mass index and perceived insufficient sleep among U.S. adults: an analysis of 2008 BRFSS data
}

Anne G Wheaton*, Geraldine S Perry, Daniel P Chapman, Lela R McKnight-Eily, Letitia R Presley-Cantrell and Janet B Croft

\begin{abstract}
Background: Over the past 50 years, the average sleep duration for adults in the United States has decreased while the prevalence of obesity and associated outcomes has increased. The objective of this study was to determine whether perceived insufficient sleep was associated with body mass index (BMI) in a national sample.

Methods: We analyzed data from the 2008 Behavioral Risk Factor Surveillance System (BRFSS) survey ( N = 384,541) in which respondents were asked, "During the past 30 days, for about how many days have you felt you did not get enough rest or sleep?" We divided respondents into six BMI categories and used multivariable linear regression and logistic regression analyses to assess the association between BMI categories and days of insufficient sleep after adjusting for sociodemographic variables, smoking, physical activity, and frequent mental distress.

Results: Adjusted mean days of insufficient sleep ranged from 7.9 (95\% confidence interval [Cl]: 7.8, 8.0) days for people of normal weight to $10.5(95 \% \mathrm{Cl}: 10.2,10.9)$ days for those in the highest weight category (BMI $\geq 40)$. Days of perceived insufficient sleep followed a linear trend across BMI categories. The likelihood of reporting $\geq 14$ days of insufficient sleep in the previous 30 days was higher for respondents in the highest weight category than for those who were normal weight (34.9\% vs. 25.2\%; adjusted odds ratio $=1.7$ (95\% Cl: 1.5, 1.8]).

Conclusion: Among U.S. adults, days of insufficient rest or sleep strongly correlated with BMI. Sleep sufficiency should be an important consideration in the assessment of the health of overweight and obese people and should be considered by developers of weight-reduction programs.
\end{abstract}

\section{Background}

Over the past 50 years, the prevalence of obesity among U.S. adults has nearly tripled from about $13 \%$ in 1960 1962 to $34 \%$ in $2007-2008$ [1,2]. Obesity is a major risk factor for many chronic diseases including type 2 diabetes, cardiovascular diseases, cancer, and obstructive sleep apnea [3-6]. As the prevalence of obesity increased, the percentage of U.S. adults who reported an average of $\leq 6$ hours of sleep per day also increased, from $22-23 \%$ in 1985 to nearly $30 \%$ in $2005-2007$ [7,8]. Results from a recent analysis of Behavioral Risk Factor Surveillance System (BRFSS) data from 2008 showed

\footnotetext{
* Correspondence: AWheaton@cdc.gov

Division of Adult and Community Health, National Center for Chronic

Disease Prevention and Health Promotion, Centers for Disease Control and Prevention, 4770 Buford Highway NE, Mailstop K-67, Atlanta, GA 30041, USA
}

that only $30 \%$ of U.S. adults felt they had received adequate sleep every night in the previous month and that more than $10 \%$ felt they had received inadequate sleep every night [9]. Causes of sleep loss other than sleep disorders include lifestyle and occupational factors [10]. Numerous cross-sectional studies have found an inverse relationship between sleep duration and body mass index (BMI) [11,12]; however, others have found a Ushaped association, with a lower BMI among people averaging 7-8 hours of sleep and a higher BMI among those with shorter and longer sleep durations [13-15]. These studies relied on subjective reports of sleep duration, but the CARDIA Sleep Study, which used an objective measure (wrist actigraphy), also found that BMI was inversely associated with sleep duration, as well as with sleep fragmentation [16]. Recent laboratory-

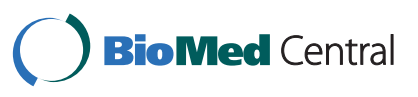


based studies have demonstrated that chronic sleep restriction may contribute to obesity by decreasing levels of leptin and increasing levels of ghrelin, hormones involved in satiety and hunger-promotion, respectively $[17,18]$.

Results of a previous analysis of 2002 BRFSS data from 18 states concerning perceived insufficient rest or sleep showed that the prevalence of obesity (defined as a BMI $\geq 30$ ) was higher among respondents who reported $\geq 14$ days of insufficient sleep in the previous 30 days than among those who reported $<14$ days [19]. To confirm and expand on these previous findings showing a positive association between multiple levels of BMI and perceived insufficient rest or sleep in a national sample, we analyzed 2008 BRFSS data and adjusted results for sociodemographic variables, as well as for smoking, physical activity, and frequent mental distress.

\section{Methods}

The BRFSS collects data through annual state-based telephone surveys of non-institutionalized U.S. civilians aged $\geq 18$ years. The surveys are conducted in all 50 states, the District of Columbia, and three U.S. territories (Guam, Puerto Rico, and the Virgin Islands). As the BRFSS is a public-use dataset, this research was exempt from review by an institutional review board. The core questionnaire of the 2008 BRFSS survey, which was administered to all survey participants, included the following question, "During the past 30 days, for about how many days have you felt you did not get enough rest or sleep?"

Survey participants' BMI was calculated from their self-reported weight and height (weight $[\mathrm{kg}] /$ height $\left[\mathrm{m}^{2}\right]$ ); and their BMI-based weight classification was determined on the basis of National Heart, Lung, and Blood Institute criteria: underweight (BMI < 18.5), normal weight $(\mathrm{BMI}=18.5-24.9)$, overweight $(\mathrm{BMI}=25.0$ $29.9)$, obese class I (BMI $=30.0-34.9)$, obese class II $(\mathrm{BMI}=35.0-39.9)$, and obese class III $(\mathrm{BMI} \geq 40)[20]$. Female survey participants were also asked whether they were currently pregnant.

In our analysis, we assessed the extent to which two measures of sleep (mean number of days of insufficient sleep and prevalence of $\geq 14$ days of insufficient sleep) were associated with BMI category. We also assessed the extent to which these measures were associated with sex, age in years $(18-24,25-34,35-44,45-54,55-64$, and 265 ), race/ethnicity (non-Hispanic white, non-Hispanic black, Hispanic, and non-Hispanic multiracial/other), education level (less than high school graduate, high school graduate or GED recipient, some college, and college graduate), smoking status (current, former, and never), recent physical activity (yes or no), and frequent mental distress (yes or no). Current smoking was defined as having smoked at least 100 cigarettes in one's lifetime and now smoking on at least "some days." Former smoking was defined as having smoked at least 100 cigarettes in one's lifetime but not currently smoking. Never smoking was defined as not having smoked at least 100 cigarettes in one's lifetime. Any recent physical activity was defined on the basis of survey participants' response to the question, "During the past month, other than your regular job, did you participate in any physical activities or exercises such as running, calisthenics, golf, gardening, or walking for exercise?" Frequent mental distress was defined on the basis of participants' response to the question, "Now thinking about your mental health, which includes stress, depression, and problems with emotions, for how many days during the past 30 days was your mental health not good?" A response of $\geq 14$ days in the previous 30 days indicated frequent mental distress.

We conducted all analyses using SAS-callable SUDAAN (version 10.0.0, Research Triangle Park, NC) to account for the complex sampling design of the BRFSS. We used multivariate linear regression analyses to calculate mean days of insufficient rest or sleep adjusted for sex, race/ethnicity, age, education level, smoking status, recent physical activity, and frequent mental distress. We used multivariate logistic regression analyses to calculate the proportion of respondents reporting $\geq 14$ days of insufficient sleep during the previous 30 days by BMI category and odds ratios (ORs) for receiving $\geq 14$ days of insufficient sleep by BMI category. All ORs were adjusted for sex, race/ethnicity, age, education level, smoking status, recent physical activity, and frequent mental distress.

\section{Results}

The median response rate to the 2008 BRFSS survey among all 50 states and the District of Columbia was 53.3\% (35.8\%-65.9\%), based on Council of American Survey and Research Organizations (CASRO) guidelines, and the median cooperation rate was $75.0 \%$ (59.3\%$87.8 \%$ ). There were 414,509 respondents to the 2008 BRFSS survey. We excluded from our analysis those with missing data for age $(\mathrm{n}=3,653)$, BMI $(\mathrm{n}=18,677)$, or days of inadequate sleep $(\mathrm{n}=7,060)$, as well as women who indicated they were pregnant, weren't sure, or did not respond to a question about their pregnancy status $(\mathrm{n}=3,237)$. After these exclusions, our study sample consisted of 384,541 U.S. adults ( $92.8 \%$ of all 2008 BRFSS survey respondents).

Weighted population characteristics are shown in Table 1. Nearly one-fifth of people were current smokers, and one-quarter reported no leisure-time physical activity in the previous month. Approximately one-tenth reported frequent mental distress. Only $1.8 \%$ of the 
Table 1 Characteristics of respondents to perceived insufficient sleep question: Behavioral Risk Factor Surveillance System Survey, 2008.

\begin{tabular}{|c|c|c|}
\hline Characteristic & $\mathrm{n}^{1}$ & $\%^{2}$ \\
\hline Total & 384,541 & 100.0 \\
\hline \multicolumn{3}{|l|}{ Sex } \\
\hline Men & 150,407 & 50.5 \\
\hline Women & 234,134 & 49.5 \\
\hline \multicolumn{3}{|l|}{ Race/Ethnicity } \\
\hline White, non-Hispanic & 305,289 & 68.9 \\
\hline Black, non-Hispanic & 29,745 & 9.8 \\
\hline Hispanic & 25,255 & 14.5 \\
\hline Other/multiracial ${ }^{3}$ & 21,051 & 6.8 \\
\hline \multicolumn{3}{|l|}{ Age } \\
\hline $18-24$ & 12,794 & 12.2 \\
\hline $25-34$ & 35,636 & 17.9 \\
\hline $35-44$ & 57,994 & 19.1 \\
\hline $45-54$ & 79,775 & 19.3 \\
\hline $55-64$ & 82,897 & 14.5 \\
\hline $65+$ & 115,445 & 17.0 \\
\hline \multicolumn{3}{|l|}{ Education Level } \\
\hline$<$ High school diploma & 36,522 & 10.9 \\
\hline High school diploma or GED & 115,468 & 28.7 \\
\hline Some college & 102,219 & 26.7 \\
\hline College graduate & 129,838 & 33.8 \\
\hline \multicolumn{3}{|l|}{ Smoker } \\
\hline Current & 65,956 & 18.7 \\
\hline Former & 114,800 & 24.6 \\
\hline Never & 202,463 & 56.6 \\
\hline \multicolumn{3}{|l|}{ Physical Activity in Past Month } \\
\hline No & 104,238 & 25.0 \\
\hline Yes & 279,924 & 75.0 \\
\hline \multicolumn{3}{|l|}{ Frequent Mental Distress ${ }^{4}$} \\
\hline No & 340,634 & 89.7 \\
\hline Yes & 39,088 & 10.4 \\
\hline \multicolumn{3}{|l|}{ BMI Category ${ }^{5}$} \\
\hline Underweight & 6,253 & 1.8 \\
\hline Normal weight & 131,009 & 35.1 \\
\hline Overweight & 141,082 & 36.4 \\
\hline Obese class I & 67,084 & 17.1 \\
\hline Obese class II & 24,609 & 6.1 \\
\hline Obese class III & 14,504 & 3.5 \\
\hline \multicolumn{3}{|l|}{ Days of Insufficient Sleep } \\
\hline 0 days & 137,781 & 30.6 \\
\hline $1-13$ days & 148,476 & 41.5 \\
\hline 14-29 days & 57,931 & 16.9 \\
\hline 30 days & 40,353 & 11.1 \\
\hline
\end{tabular}

${ }^{1}$ Unweighted n's. Categories may not sum to survey total because of missing responses.

${ }^{2}$ Weighted percentage.

${ }^{3}$ Asian, Native Hawaiian or Other Pacific Islander, American Indian/Alaska Native, or multiracial.

${ }^{4}$ Frequent mental distress: Mental health, including stress, depression, and problems with emotions, was not good for $\geq 14$ days in past 30 days.

${ }^{5} \mathrm{BMI}$ categories: underweight (BMI < 18.5), normal weight $(18.5 \leq \mathrm{BMI}<25)$, overweight $(25 \leq \mathrm{BMI}<30)$, obese class I (30 $\left.\leq \mathrm{BMI}<35\right)$, obese class II (35 $\leq \mathrm{BMI}$

$<40)$, obese class III (BMI $\geq 40)$. 
population was underweight, $35.1 \%$ was normal weight, $36.4 \%$ was overweight, $17.1 \%$ was obese class I, $6.1 \%$ was obese class II, and 3.5\% was obese class III. Approximately $30 \%$ reported 0 days of insufficient sleep or rest, and $11.1 \%$ reported getting insufficient rest or sleep all of the previous 30 days.
Among all adults, the adjusted mean number of insufficient days of sleep in the previous 30 days was 8.6 (95\% CI: 8.5, 8.6) (Table 2). The mean number of days was higher among women than among men (9.1 and 8.0, respectively $[\mathrm{p}<0.05]$ ) and lower among Hispanics than among members of other racial/ethnic groups. In

Table 2 Perceived insufficient sleep among U.S. adults, aged $\geq 18$ years, by selected characteristics: BRFSS, 2008.

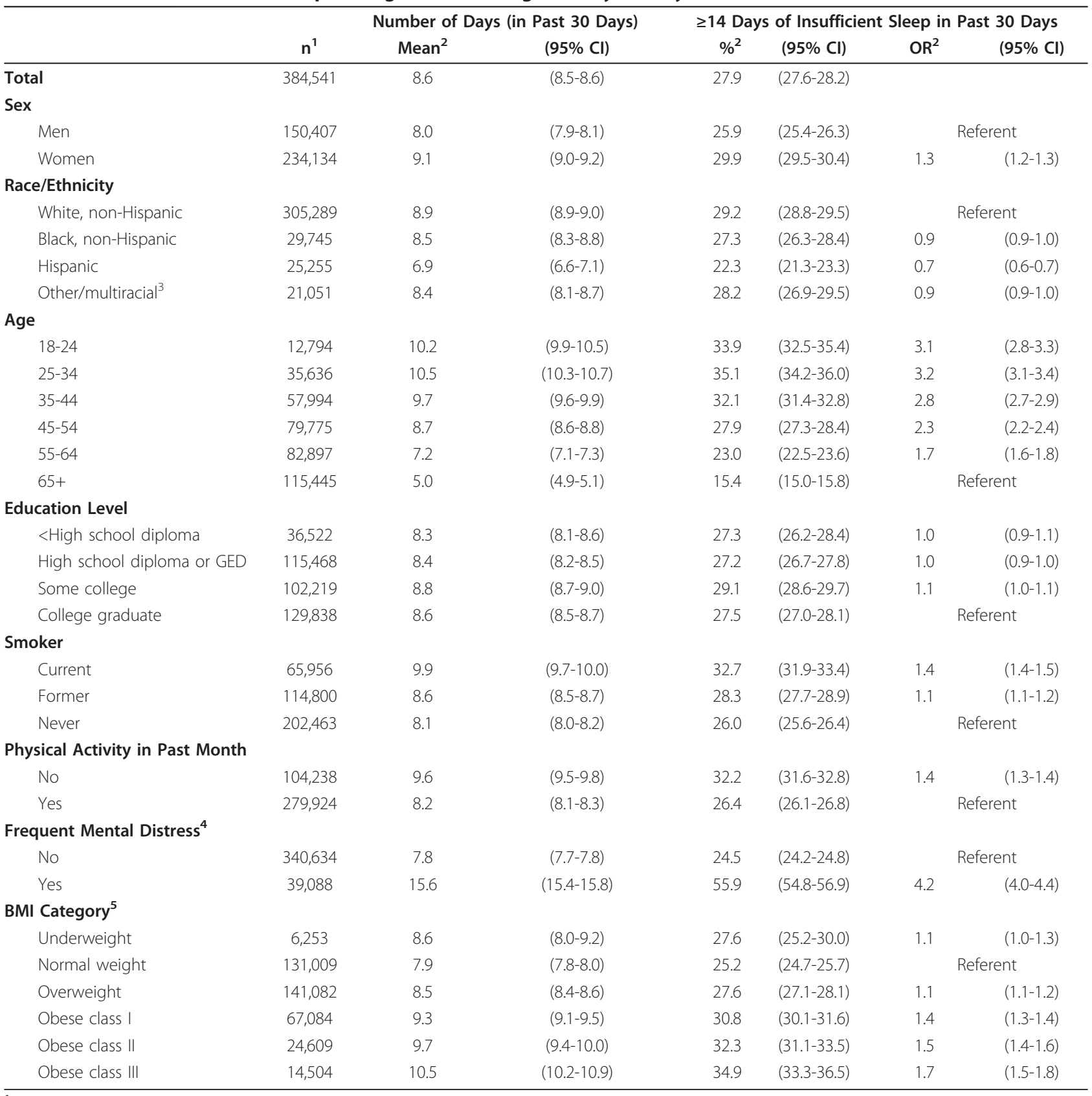

\footnotetext{
${ }^{1}$ Unweighted n's.

${ }^{2}$ Weighted means, proportions, and odds ratios adjusted for all other variables in the table.

${ }^{3}$ Asian, Native Hawaiian or Other Pacific Islander, American Indian/Alaska Native, or multiracial.

${ }^{4}$ Frequent mental distress: Mental health, including stress, depression, and problems with emotions, was not good for $\geq 14$ days in past 30 days.

${ }^{5}$ Underweight (BMI < 18.5), normal weight $(18.5 \leq \mathrm{BMI}<25)$, overweight $(25 \leq \mathrm{BMI}<30)$, obese class I $(30 \leq \mathrm{BMI}<35)$, obese class II $(35 \leq \mathrm{BMI}<40)$, obese class III (BMI $\geq 40)$.
} 
general, age was inversely associated with days of insufficient sleep, with adults aged 18-34 reporting the most days of insufficient sleep, and those aged 65 or older reporting the fewest. The mean number of days of insufficient sleep ranged from 8.3 days among individuals without a high school diploma to 8.8 days among those with some college; was higher among current smokers than among nonsmokers; and higher among people who reported no leisure-time physical activity in the previous month than among those who reported at least some such activity. The mean number of days of insufficient sleep was 15.6 days among adults who reported frequent mental distress, compared to 7.8 days for adults without frequent mental distress.

Overall, $27.9 \%$ of adults reported $\geq 14$ days of insufficient sleep in the previous 30 days (Table 2). The percentage who did so was higher among women than among men (29.9\% vs. $25.9 \%, \mathrm{p}<0.05)$; lower among Hispanics than among members of the other racial/ ethnic groups; lower among those aged 65 or older (15.4\%) than among those aged 25-34 (35.1\%); higher among those with some college education; lower among never smokers than among former smokers and current smokers (26.0\% vs. $28.3 \%$ and $32.7 \%$, respectively, $\mathrm{p}<0.05$ ); and higher among those who reported no leisure-time physical activity in the previous month than among those who reported some such activity (32.2\% vs. $26.4 \%, \mathrm{p}<0.05)$. More than half of adults who reported frequent mental distress also reported $\geq 14$ days of insufficient sleep in the previous 30 days, compared to about a quarter of adults without frequent mental distress.

When adjusted for sociodemographic characteristics, smoking status, recent physical activity, and frequent mental distress, the mean number of days of insufficient sleep ranged from 7.9 (95\% CI, 7.8, 8.0) for people in the normal-weight category to 10.5 (95\% CI, 10.2, 10.9) for those in the obese class III category. The mean number was also higher for people who were underweight $(8.6$ [95\% CI, 8.0, 9.2]) than for those of normal weight. A quarter of normal-weight people reported $\geq 14$ days of insufficient sleep in the previous month, compared with $34.9 \%$ of those in the obese class III category.

We observed a clear, positive gradient relationship between days of insufficient sleep and BMI-based weight categories from normal weight through obese class III among both men and women (Figure 1), all racial/ethnic groups (Figure 2), and all age groups (Figure 3). Although the number of days of insufficient sleep was generally higher among people in the underweight category than among those in the normalweight category, the difference was not always statistically significant.

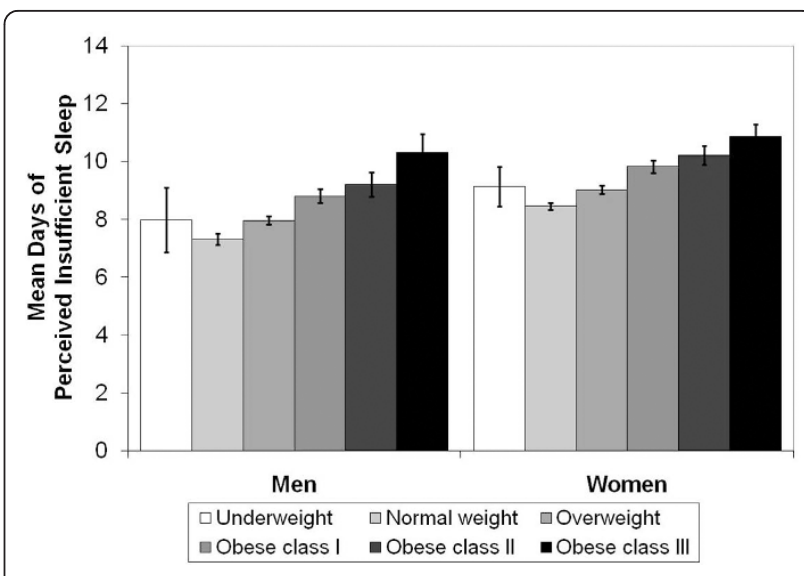

Figure 1 Mean ( $\pm 95 \%$ confidence intervals) days of perceived insufficient sleep in previous 30 days by BMI category and sex. Means adjusted for race, age, education, smoking, recent physical activity, and frequent mental distress.

\section{Discussion}

Most studies that have assessed the association between BMI and sleep have used self-reported usual sleep duration as their sleep measure. As noted previously, results from many of these studies have shown a simple inverse relationship between sleep duration and BMI, whereas results from others have shown a U-shaped relationship, with a higher BMI associated with both short and long sleep durations [21-23]. Other study results have shown increased morbidity and mortality risk among people reporting either short or long sleep durations [24-27]. We detected a strong association between days of insufficient sleep and BMI category except among people classified as underweight. A likely explanation for this exception to our overall finding is that the prevalence of conditions that both cause weight loss and disrupt sleep,

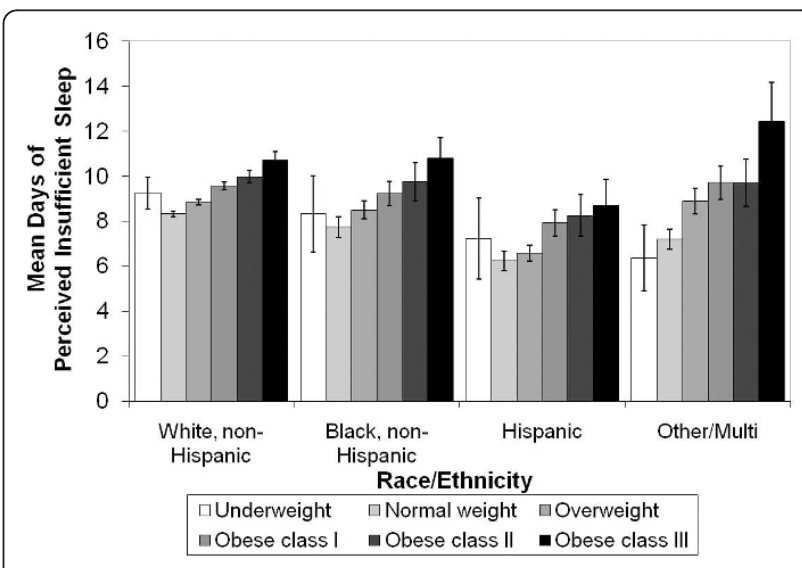

Figure 2 Mean ( $\pm 95 \%$ confidence intervals) days of perceived insufficient sleep in previous 30 days by BMI category and race/ethnicity. Means adjusted for sex, age, education, smoking, recent physical activity, and frequent mental distress. 


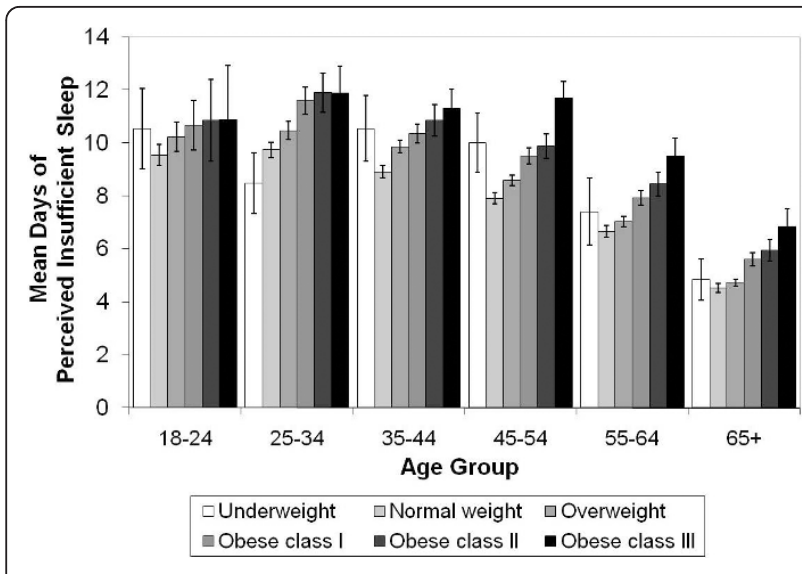

Figure 3 Mean ( $\pm 95 \%$ confidence intervals) days of perceived insufficient sleep in previous 30 days by BMI category and age. Means adjusted for sex, race, education, smoking, recent physical activity, and frequent mental distress.

such as eating disorders, cancer, or other chronic diseases, may be higher in the underweight group.

Some study results have shown that the association between obesity (or BMI) and sleep duration differs by sex; however, the direction of the difference has not been consistent. For example, Kripke et al. found a negative association between sleep duration and BMI among men but a U-shaped relationship among women [28]; Cournot et al. reported that short sleep duration was associated with higher BMI among women but not among men [29]; and results of a study conducted in Hong Kong showed a negative association between sleep duration and BMI among men but not among women [30]. Longitudinal studies that have examined changes in weight with sleep duration or sleep problems have also been inconsistent. In a longitudinal study from Finland, sleep problems such as trouble falling asleep and trouble staying asleep were associated with major weight gain during a 5- to 7-year follow up among middle-aged women, but not men [31]. In contrast, short sleep duration was associated with weight gain at 1-year follow up in a large Japanese study among men, but not women [32]. Although we observed that women experienced more days of insufficient sleep than men, we saw a similar positive association between BMI and number of days of insufficient sleep among each.

We found that Hispanics had fewer days of insufficient sleep than blacks or whites. Results from the 2004-2007 National Health Interview Survey similarly showed that Mexican-Americans were more likely to experience long sleep duration than other race/ethnicities, although they also indicated that non-Hispanic blacks were more likely to experience both short and long sleep duration than were non-Hispanic whites [33]. In the CARDIA Sleep Study, time in bed, sleep duration, sleep latency (time between going to bed and falling asleep), and sleep efficiency (percentage of time in bed spent sleeping) varied by both race and sex: white women had the longest sleep duration, highest sleep efficiency, and shortest sleep latency, and black men had the shortest sleep duration, lowest sleep efficiency, and longest sleep latency [34].

Individuals aged 65 years or older reported the fewest days of insufficient sleep in the present study, and individuals aged 25-34 reported the most. In contrast, results of an analysis of data from the 2004-2007 National Health Interview Survey showed that older adults were more likely to report short and long sleep durations and that younger age was associated only with long sleep duration [33]. Among women enrolled as controls in the Collaborative Breast Cancer Study, age was negatively associated with hours of sleep [14]; the results of this study also showed that sleep duration was negatively associated with risk for obesity among women aged 50 or older as well as among those younger than 50 [14]. We similarly observed a positive association between days of insufficient sleep and BMI category across all age groups.

The prevalence of frequent insufficient sleep was higher among current and former smokers than among never smokers and among those who reported no recent leisure-time physical activity than among those who reported some such activity. This association between unhealthy behaviors and insufficient sleep is supported by previous analysis of National Health Interview Survey data that demonstrated that smoking and physical inactivity were more prevalent among individuals who slept less than 6 hours compared to those who slept 7 or 8 hours [35].

Whereas most studies of the relationship between BMI and sleep have used sleep duration as the measure for sleep, we used days of perceived insufficient rest or sleep. Comparison of the measure used in our study with self-reported sleep duration, snoring, and daytime sleepiness in the same population will enable us to refine our conclusions. One limitation to using sleep duration as the sole measure for sleep is that such a measure does not address the quality of sleep. Even people who sleep for a relatively long time may not get adequate quality sleep because their sleep is disrupted by sleep-disordered breathing, sleep disorders such as insomnia, the side-effects of various medications, or other unknown causes. Results of studies comparing self-reported sleep duration with objectively measured sleep duration have shown that people with poorer sleep quality reported sleeping for shorter periods than those with better sleep quality, although the measured sleep duration for the two groups was the same $[36,37]$. 
One recent study addressed the issue of sleep quality in an investigation of sleep duration and BMI. As part of the CARDIA Sleep Study, Lauderdale et al. [16] used wrist actigraphy to obtain objective measures of sleep duration and sleep fragmentation and also collected data on apnea symptoms, including snoring and tiredness. They found that both shorter sleep duration and greater sleep fragmentation were associated with higher BMI in unadjusted models, although adjustment for confounders (i.e., sociodemographic factors, smoking status, physical activity, and apnea risk factors) decreased the association between sleep duration and BMI and eliminated the association between sleep fragmentation and BMI, possibly because of the adjustment for snoring.

Our findings are subject to several limitations. First, the wording used in the insufficient sleep question is open to interpretation. For instance, respondents may interpret "enough" to mean at least a specific number of hours or rather sufficient time to awaken refreshed. The question also does not distinguish between "rest" and "sleep". Also, BRFSS data are collected through telephone surveys of the civilian, non-institutionalized population, therefore our findings are not generalizable to military personnel, institutionalized persons, and persons residing in households without landline telephones. Finally, the cross-sectional nature of the survey prevented us from attempting to determine the causal relationship between BMI and sleep. However, there is growing evidence that excess weight and insufficient and/or poor quality sleep may have a reciprocal causal relationship. Obesity has been shown to increase the risk for obstructive sleep apnea syndrome, a disorder characterized by frequent disruption of breathing during sleep caused by closure of the airways [38-40]. These abnormal breathing patterns result in disturbed sleep. Excess weight is strongly associated with the prevalence of sleep apnea, as well as with the frequency of disordered-breathing events and with oxygen desaturation $[41,42]$. In recent years, results from a few prospective cohort studies have shown weight gain to be associated with an increased risk of developing sleep apnea [38-40], and clinical trial results have shown weight loss among sleep apnea patients to be associated with a decrease in the severity of sleep apnea [43-45]. On the other hand, there is also evidence that chronic sleep disruption may alter appetite regulation by changing levels of hormones such as leptin and ghrelin $[17,18]$. One advantage to using BRFSS data, however, is that the large sample size of the BRFSS survey allowed us to assess the relationship between BMI and insufficient sleep for various subgroups based on sex, age, and race/ethnicity.

\section{Conclusion}

The results of our analysis, which showed a strong graded association between days of perceived insufficient sleep and weight status across all levels of BMI among U.S. adults, suggest that the possible effect of excess weight on sleep should be considered by developers of programs to address sleep disorders and that the possible effect of insufficient sleep on weight should be considered by developers of weight-reduction programs. Although sleep specialists commonly discuss with their patients how obesity may increase the risk for sleep disorders, they should also address the possibility that even smaller amounts of excess weight, as seen in overweight individuals, may be detrimental to their health and welfare.

\section{Acknowledgements}

This publication/project was made possible through a cooperative agreement between the Association for Prevention Teaching and Research (APTR) and the Centers for Disease Control and Prevention (CDC), award number 3U50CD300860; its contents are the responsibility of the authors and do not necessarily reflect the official position of APTR or CDC. Disclaimer: The findings and conclusions in this report are those of the authors and do not necessarily represent the official position of the Centers for Disease Control and Prevention.

\section{Authors' contributions}

AW performed data analysis and drafted the manuscript. All authors contributed to the interpretation of the results and preparation and approval of the final manuscript.

\section{Competing interests}

The authors declare that they have no competing interests.

Received: 17 September 2010 Accepted: 10 May 2011

Published: 10 May 2011

\section{References}

1. Flegal KM, Carroll MD, Ogden CL, Curtin LR: Prevalence and trends in obesity among US adults, 1999-2008. JAMA 2010, 303:235-241.

2. Flegal KM, Carroll MD, Kuczmarski RJ, Johnson CL: Overweight and obesity in the United States: prevalence and trends, 1960-1994. Int J Obes Relat Metab Disord 1998, 22:39-47.

3. Harris MI, Flegal KM, Cowie CC, Eberhardt MS, Goldstein DE, Little RR, Wiedmeyer HM, Byrd-Holt DD: Prevalence of diabetes, impaired fasting glucose, and impaired glucose tolerance in U.S. adults. The Third National Health and Nutrition Examination Survey, 1988-1994. Diabetes Care 1998, 21:518-524.

4. Hubert HB, Feinleib M, McNamara PM, Castelli WP: Obesity as an independent risk factor for cardiovascular disease: a 26-year follow-up of participants in the Framingham Heart Study. Circulation 1983, 67:968-977.

5. Hjartaker A, Langseth $H$, Weiderpass E: Obesity and diabetes epidemics: cancer repercussions. Adv Exp Med Biol 2008, 630:72-93.

6. Al Lawati NM, Patel SR, Ayas NT: Epidemiology, risk factors, and consequences of obstructive sleep apnea and short sleep duration. Prog Cardiovasc Dis 2009, 51:285-293.

7. Williams GD, Dufour M, Bertolucci D: Drinking levels, knowledge, and associated characteristics, 1985 NHIS findings. Public Health Rep 1986, 101:593-598

8. Schoenborn CA, Adams PF: Health behaviors of adults: United States, 2005-2007. Vital Health Stat 2010, 10.

9. McKnight-Eily LR, Liu Y, Perry GS, Presley-Cantrell LR, Strine TW, Lu H, Croft JB: Perceived insufficient rest or sleep among adults - United States, 2008. MMWR Morb Mortal Wkly Rep 2009, 58:1175-1179.

10. Institute of Medicine (U.S.). Committee on Sleep Medicine and Research: Sleep disorders and sleep deprivation: an unmet public health problem. Edited by: Colten HR, Altevogt BM. Washington, DC: Institute of Medicine: National Academies Press; 2006: 
11. Theorell-Haglow J, Berne C, Janson C, Sahlin C, Lindberg E: Associations between short sleep duration and central obesity in women. Sleep 2010, 33:593-598.

12. Patel SR, Blackwell T, Redline S, Ancoli-Israel S, Cauley JA, Hillier TA, Lewis CE, Orwoll ES, Stefanick ML, Taylor BC, Yaffe K, Stone KL: The association between sleep duration and obesity in older adults. Int $\mathrm{J}$ Obes (Lond) 2008, 32:1825-1834.

13. Hairston KG, Bryer-Ash M, Norris JM, Haffner S, Bowden DW, Wagenknecht LE: Sleep duration and five-year abdominal fat accumulation in a minority cohort: the IRAS family study. Sleep 2010, 33:289-295.

14. Anic GM, Titus-Ernstoff L, Newcomb PA, Trentham-Dietz A, Egan KM: Sleep duration and obesity in a population-based study. Sleep Med 2010, 11:447-451.

15. Lopez-Garcia E, Faubel R, Leon-Munoz L, Zuluaga MC, Banegas JR, Rodriguez-Artalejo F: Sleep duration, general and abdominal obesity, and weight change among the older adult population of Spain. Am J Clin Nutr 2008, 87:310-316.

16. Lauderdale DS, Knutson KL, Rathouz PJ, Yan LL, Hulley SB, Liu K: Crosssectional and longitudinal associations between objectively measured sleep duration and body mass index: the CARDIA Sleep Study. Am J Epidemiol 2009, 170:805-813.

17. Spiegel K, Tasali E, Leproult R, Van Cauter E: Effects of poor and short sleep on glucose metabolism and obesity risk. Nat Rev Endocrinol 2009, 5:253-261.

18. Van Cauter E, Holmback U, Knutson K, Leproult R, Miller A, Nedeltcheva A, Pannain S, Penev P, Tasali E, Spiegel K: Impact of sleep and sleep loss on neuroendocrine and metabolic function. Horm Res 2007, 67(Suppl 1):2-9.

19. Strine TW, Chapman DP: Associations of frequent sleep insufficiency with health-related quality of life and health behaviors. Sleep Med 2005, 6:23-27.

20. National Institutes of Health: Clinical Guidelines on the Identification, Evaluation, and Treatment of Overweight and Obesity in Adults-The Evidence Report. Obes Res 1998, 6(Suppl 2):51S-209S.

21. Cappuccio FP, Taggart FM, Kandala NB, Currie A, Peile E, Stranges S, Miller MA: Meta-analysis of short sleep duration and obesity in children and adults. Sleep 2008, 31:619-626.

22. Singh $\mathrm{M}$, Drake $\mathrm{CL}$, Roehrs $\mathrm{T}$, Hudgel DW, Roth $\mathrm{T}$ : The association between obesity and short sleep duration: a population-based study. J Clin Sleep Med 2005, 1:357-363.

23. Spiegel K: Sleep loss as a risk factor for obesity and diabetes. Int J Pediatr Obes 2008, 3(Suppl 2):27-28.

24. Gallicchio L, Kalesan B: Sleep duration and mortality: a systematic review and meta-analysis. J Sleep Res 2009, 18:148-158.

25. Qureshi Al, Giles WH, Croft JB, Bliwise DL: Habitual sleep patterns and risk for stroke and coronary heart disease: a 10-year follow-up from NHANES I. Neurology 1997, 48:904-911.

26. Ayas NT, White DP, Al-Delaimy WK, Manson JE, Stampfer MJ, Speizer FE, Patel S, Hu FB: A prospective study of self-reported sleep duration and incident diabetes in women. Diabetes Care 2003, 26:380-384.

27. Ayas NT, White DP, Manson JE, Stampfer MJ, Speizer FE, Malhotra A, Hu FB: A prospective study of sleep duration and coronary heart disease in women. Arch Intern Med 2003, 163:205-209.

28. Kripke DF, Garfinkel L, Wingard DL, Klauber MR, Marler MR: Mortality associated with sleep duration and insomnia. Arch Gen Psychiatry 2002, 59:131-136.

29. Cournot M, Ruidavets JB, Marquie JC, Esquirol Y, Baracat B, Ferrieres J: Environmental factors associated with body mass index in a population of Southern France. Eur J Cardiovasc Prev Rehabil 2004, 11:291-297.

30. Ko GT, Chan JC, Chan AW, Wong PT, Hui SS, Tong SD, Ng SM, Chow F, Chan CL: Association between sleeping hours, working hours and obesity in Hong Kong Chinese: the 'better health for better Hong Kong' health promotion campaign. Int J Obes (Lond) 2007, 31:254-260.

31. Lyytikainen P, Lallukka T, Lahelma E, Rahkonen O: Sleep problems and major weight gain: a follow-up study. Int J Obes (Lond)

32. Watanabe M, Kikuchi H, Tanaka K, Takahashi M: Association of short sleep duration with weight gain and obesity at 1-year follow-up: a large-scale prospective study. Sleep 2010, 33:161-167

33. Krueger PM, Friedman EM: Sleep duration in the United States: a crosssectional population-based study. Am J Epidemiol 2009, 169:1052-1063.
34. Lauderdale DS, Knutson KL, Yan LL, Rathouz PJ, Hulley SB, Sidney S, Liu K: Objectively measured sleep characteristics among early-middle-aged adults: the CARDIA study. Am J Epidemio/ 2006, 164:5-16.

35. Schoenborn CA, Adams PF: Sleep duration as a correlate of smoking, alcohol use, leisure-time physical inactivity, and obesity among adults: United States, 2004-2006. Book Sleep duration as a correlate of smoking, alcohol use, leisure-time physical inactivity, and obesity among adults: United States, 2004-2006 City: National Center for Health Statistics; 2008, (Editor ed. ^eds.).

36. Lauderdale DS, Knutson KL, Yan LL, Liu K, Rathouz PJ: Self-reported and measured sleep duration: how similar are they? Epidemiology 2008, 19:838-845.

37. Regestein $Q R$, Friebely J, Shifren JL, Scharf MB, Wiita B, Carver J, Schiff I: Self-reported sleep in postmenopausal women. Menopause 2004, 11:198-207.

38. Peppard PE, Young T, Palta M, Dempsey J, Skatrud J: Longitudinal study of moderate weight change and sleep-disordered breathing. JAMA 2000 284:3015-3021.

39. Newman AB, Foster G, Givelber R, Nieto FJ, Redline S, Young T: Progression and regression of sleep-disordered breathing with changes in weight: the Sleep Heart Health Study. Arch Intern Med 2005, 165:2408-2413.

40. Tishler PV, Larkin EK, Schluchter MD, Redline S: Incidence of sleepdisordered breathing in an urban adult population: the relative importance of risk factors in the development of sleep-disordered breathing. JAMA 2003, 289:2230-2237.

41. Crummy F, Piper AJ, Naughton MT: Obesity and the lung: 2. Obesity and sleep-disordered breathing. Thorax 2008, 63:738-746.

42. Peppard PE, Ward NR, Morrell MJ: The impact of obesity on oxygen desaturation during sleep-disordered breathing. Am J Respir Crit Care Med 2009, 180:788-793.

43. Phillips CL, Yee BJ, Trenell MI, Magnussen JS, Wang D, Banerjee D, Berend N, Grunstein RR: Changes in regional adiposity and cardiometabolic function following a weight loss program with sibutramine in obese men with obstructive sleep apnea. J Clin Sleep Med 2009, 5:416-421

44. Greenburg DL, Lettieri CJ, Eliasson AH: Effects of surgical weight loss on measures of obstructive sleep apnea: a meta-analysis. Am J Med 2009, 122:535-542.

45. Young T, Peppard PE, Gottlieb DJ: Epidemiology of obstructive sleep apnea: a population health perspective. Am J Respir Crit Care Med 2002, 165:1217-1239.

\section{Pre-publication history}

The pre-publication history for this paper can be accessed here: http://www.biomedcentral.com/1471-2458/11/295/prepub

doi:10.1186/1471-2458-11-295

Cite this article as: Wheaton et al:: Relationship between body mass index and perceived insufficient sleep among U.S. adults: an analysis of 2008 BRFSS data. BMC Public Health 2011 11:295.

\section{Submit your next manuscript to BioMed Central and take full advantage of:}

- Convenient online submission

- Thorough peer review

- No space constraints or color figure charges

- Immediate publication on acceptance

- Inclusion in PubMed, CAS, Scopus and Google Scholar

- Research which is freely available for redistribution 